\title{
Ankle Fractures: Review Article
}

Sheena Seewoonarain ${ }^{1 *}$, M Prempeh $^{1}$, M Shakokani $^{1}$ and A Magan ${ }^{1,2}$

${ }^{1}$ Department of Orthopaedics, Ipswich Hospital NHS Trust, Heath Road, Ipswich, UK

${ }^{2}$ Department of Orthopaedics, Addenbrookes-Cambridge University Hospital NHS Foundation Trust, UK

*Corresponding author: Sheena Seewoonarain, BSc, MBBS, MRCS, Department of Orthopaedics, Ipswich Hospital NHS Trust, Health Road, Ipswich, IP4 5PD, Tel: +44 1473 712233; E-mail: sseewoonarain@gmail.com

Rec date: December 08, 2015; Acc date: January 31, 2016; Pub date: February 09, 2016

Copyright: (c) 2016 Seewoonarain S, et al. This is an open-access article distributed under the terms of the Creative Commons Attribution License, which permits unrestricted use, distribution, and reproduction in any medium, provided the original author and source are credited.

\begin{abstract}
Ankle fractures are a common injury associated with trauma in the young patient and osteoporosis in the elderly patient. They can be associated with significant morbidity and challenging to manage. These patients are at an increased risk of developing post traumatic ankle arthritis as well as other complications. Therefore a systematic approach to the management of ankle fractures is required. We review the anatomy, clinical presentation and discuss the management options and potential complications commonly encountered in these injuries.
\end{abstract}

\section{Introduction}

Ankle injuries are common and account for more than five million emergency department consultations annually [1]. Interestingly, 85\% of these ankle injuries are ankle sprains and the remaining $15 \%$ are ankle fractures [2]. Overall ankle fractures constitute $9 \%$ of fractures and are the most common injuries involving articular surface of a weight bearing joint $[3,4]$. Often, ankle fractures are isolated injuries and up to one in four will require surgical intervention. One in twenty ankle fractures are associated with other fractures. Patients with polytrauma, who survived their initial injuries, are more likely to suffer from functional impairment if foot and ankle injuries were also present [5].

The average age of a patients presenting to emergency department is 46 , although there is a bimodal age distribution with peaks in older females and young males. There has been a three-fold rise in incidence in the older females over the past three decades because of an aging population $[3,6]$. There has also been a surge in the number of open ankle fractures amongst the elderly following low energy trauma such as a falls from standing height. Ankle fractures are an increasing problem due to the increasing aging population [3].

A high proportion of patients with ankle fractures are at risk of developing post traumatic ankle osteoarthritis in addition to other complications [7]. This can significantly impact the quality of life and lead to increased mortality in the most severe cases [7]. Therefore the primary intervention is to restore the normal anatomy. In this article we review the anatomy and management of ankle fractures and discuss the potential treatment options as well as complications.

\section{Anatomy}

The ankle joint is a complex hinge joint consisting of the distal part of the tibia and fibula which articulate with the body of the talus. The majority of articulation occurs between the surface of the talus and tibial plafond. The posterior part of the tibial plafond forms the posterior malleolus, the medial distal tibia forms the medial malleolus and distal fibular forms the lateral malleolus. This joint is capable of plantar-flexion, dorsi-flexion as well as sliding and rolling movements.
It is most unstable in plantar flexion as the talus is narrowest posteriorly and most injuries occur in this position [8].

The ankle joint is vital for maintaining posture and ambulation. The congruency and stability of the joint are maintained by a combination of the bony components, surrounding ligaments, tendons, musculature and joint capsule. The lateral ligament is composed of three structures: the anterior and posterior talofibular ligament with the calcaneofibular ligament running between them. Medially, the deltoid ligament which is made up of a superficial part attached to the medial malleolus, talar neck and calcaneum and the deep part which is attached to the medial malleolus and talus. The deltoid is the stronger ligament and its disruption influences the management of ankle fracture. The distal tibia and fibula form a fibrous joint called the distal tibiofibular syndesmosis, which is made up of four ligaments and two bones. The distal tibiofibular syndesmosis contributes to ankle stability and maintains the anatomical position of the ankle to form the ankle mortise.

The ankle has the smallest surface area out of the major weight bearing joints with the talar dome bearing more weight per unit area than any other joint surface. During ambulation, the stress placed across the joint ranges from 1.25 to 5.5 times normal body weight depending on activity [9]. Despite being one of the most congruous joints with a low risk of osteoarthritis, minor disruptions to congruency can lead to arthritic changes in the long term. It has been shown that $1 \mathrm{~mm}$ of talar shift can lead to a $42 \%$ reduction in the tibiotalar contact area causing a $49 \%$ increase in the joint contact pressure [10-12].

\section{Classification}

It was Percival Pott who developed the first classification system for ankle fractures describing the injury by the number of malleoli involved thus unimalleolar, bimalleolar and trimalleolar fractures [13].

The Danis-Weber classification was first developed by Danis in 1940 and later modified by Weber in 1966 (Table 1). It is based upon the level of the distal fibula fracture. The higher the fibular fracture, the greater the risk of instability and need for surgical intervention. 
Although this is a simple classification it does not take into account injury to medial structures $[14,15]$.

\begin{tabular}{|l|l|}
\hline Type & Description \\
\hline A & $\begin{array}{l}\text { Fracture below the level of syndesmosis (infrasyndesmotic) } \\
\text { Correlates with supination adduction injury } \\
\text { Mostly stable }\end{array}$ \\
\hline B & $\begin{array}{l}\text { Fracture at the level of syndesmosis (transyndesmotic) } \\
\text { Considered unstable if associated with medial malleolus or deltoid } \\
\text { ligament injury } \\
\text { Correlates with supination external rotation injury }\end{array}$ \\
\hline C & $\begin{array}{l}\text { Fracture above the level of syndesmosis (suprasyndesmotic) } \\
\text { Considered unstable if associated with medial malleolus or deltoid } \\
\text { ligament injury } \\
\text { Correlates with pronation abduction and pronation external rotation } \\
\text { injury }\end{array}$ \\
\hline
\end{tabular}

Table 1: The Danis-Weber classification of ankle fractures.

An alternative classification system, devised by Lauge-Hansen in 1950, was based upon the position of the foot at the time of injury and the direction of the deforming force and noted the subsequent fracture pattern in freshly amputated limbs (Table 2). The injury is governed by two factors, firstly the position of the foot (pronation or supination) and secondly the direction of force (abduction, adduction or external rotation). This system predicts the bone and soft tissue injuries and pioneered the way for the closed treatment of ankle fractures [16].

\section{Clinical presentation}

The most common cause of ankle fractures is a fall (37.5\%), followed by inversion injuries (31.5\%) and then sports related injuries (10.2\%) [3]. Diabetic patients may present with a history of minor trauma or may not recall trauma at all if they have peripheral neuropathy. High energy injuries with axial loading may result in more serious tibial plafond, or pilon fractures, and compartment syndrome of the leg [17].

\begin{tabular}{|l|l|}
\hline Type & Description \\
\hline $\begin{array}{l}\text { Supination-External } \\
\text { Rotation (SER) }\end{array}$ & $\begin{array}{l}\text { Composed of lateral oblique fibula fracture and possible } \\
\text { medial malleolus fracture or deltoid ligament injury } \\
\text { Most common ankle fracture } \\
\text { Fibular fracture correlates to Weber B }\end{array}$ \\
\hline $\begin{array}{l}\text { Pronation-External } \\
\text { Rotation (PER) }\end{array}$ & $\begin{array}{l}\text { Composed of fibula fracture above the joint level and } \\
\text { may be as high as the fibula neck with medial malleolus } \\
\text { or deltoid ligament injury } \\
\text { Correlates to Weber C }\end{array}$ \\
\hline $\begin{array}{l}\text { Supination-Adduction } \\
\text { (SA) }\end{array}$ & $\begin{array}{l}\text { Composed of fibula fracture below the joint level with } \\
\text { vertical medial malleolus fracture and impaction of the } \\
\text { plafond } \\
\text { Correlates to Weber A }\end{array}$ \\
\hline $\begin{array}{l}\text { Pronation- } \\
\text { Abduction(PA) }\end{array}$ & $\begin{array}{l}\text { Composed of comminuted fibula fracture above the joint } \\
\text { level with medial malleolus or deltoid ligament injury }\end{array}$ \\
\hline
\end{tabular}

Table 2: The Lauge-Hansen classification of ankle fractures.

Patients will frequently present with pain, bruising, swelling of the ankle and inability to weight bear. Patients with an open injury, dislocation or the presence of neurovascular compromise must be identified. Areas of maximal tenderness should be identified including the malleoli and palpation the entire fibula to exclude a Maisonneuve injury (associated high fibular fracture), deltoid ligament and midfoot for associated injuries [18].

It is important to note other medical comorbidities such as diabetes, smoking and peripheral vascular disease, all of which can lead to delayed bone union and poor wound healing. Diabetic patients are at particular risk with peripheral neuropathy and require well-padded casts and regular skin inspection. The patient's social history should also be recorded including mobility status and functional requirements to aid in individual tailored care $[19,20]$.

\section{Investigation}

The primary mode of investigation is a standard radiological series of the ankle including an anterior-posterior (AP) view, lateral view and mortise view. The mortise view is taken with the foot internally rotated by 15 degrees thus the X-ray beam is perpendicular to the intermalleolar line, demonstrating the ankle mortise, an area of equidistant joint space between the tibial plafond and talar dome. The lateral view also visualises the posterior malleolus. In cases where there is clinical tenderness of the proximal leg then full-length radiographs of the tibia and fibula are obtained to detect a Maisonneuve injury.

In more complex cases, including those affecting the tibia articular surface or growth plate, more detailed imaging may be required in the form of computer tomography (CT) or magnetic resonance imaging (MRI).

\section{Treatment Option}

The principles of treatment are to restore anatomical alignment and joint congruity to ensure stability, which will in turn reduce long term complications. This involves urgent reduction of grossly displaced or dislocated joints in the emergency department with documentation of neurovascular status before and after reduction. Initial immobilisation in a splint or cast is applied with a check X-ray. Complex fractures involving the tibial plafond, talus and associated soft tissue injury may require further imaging.

Open fractures require tetanus prophylaxis and antibiotic coverage. Debridement, removal of any foreign material and flushing of the area should be undertaken as the earliest but safest time. This reduces the bacterial load in the wound thus minimising the chance of infection. If there is a delay in definitive management due to open wounds an external fixator may be employed to maintain the reduction [21-23].

Once the fracture is immobilised, the decision for definitive treatment can be made based upon two factors: congruency of the tibiotalar joint and stability. This can be detected by medial joint tender tenderness clinically and displacement of the tibiotalar joint radiographically commonly called talar shift. In cases that can be difficult to assess, further stress views radiographs or fluoroscopy under anaesthesia can help to evaluate joint stability.

\section{Non operative Treatment}

Fractures that are considered stable can be treated conservatively in a cast or moonboot for a period of at least six weeks [24]. Stable fractures include those with an isolated undisplaced medial or lateral malleoli fractures without significant talar shift (less than $4 \mathrm{~mm}$ ). Posterior malleolus fractures are also treated non-operatively if they involve less than $25 \%$ of the articular surface [1]. The advantages of non-surgical intervention are less risk of wound complications, blood 
clots and anaesthetic related complications. However, the main drawback of conservative management is that patients require regular follow up with serial radiographs to ensure fracture alignment is maintained.

\section{Operative Treatment}

Unstable fractures are treated surgically unless contraindicated by significant co-morbidities. The indication for surgery include; open fractures, unstable (bimalleolar fractures) or displaced fracture and those with neurovascular compromise. Posterior malleolar fractures should be fixed if the fragment is more than twenty-five percent of the joint surfaces of the distal tibia as viewed on a lateral radiograph. Some may contend that this value is difficult to interpret via radiographs.

Operative management of ankle fractures mainly includes open reduction and internal fixation, using plates and screws. Alternative techniques include the use tension band wires or external fixators in complex fractures. External fixators are often used in open fractures with significant comminution that are not amenable to other fixation methods as well as high energy periarticular fractures such ankle pilon or tibial plateau fractures.It is important during surgery of ankle fractures to assess the tibiofibular syndesmosis and intraoperatively the hook test, can be used to assess the integrity of the syndesmosis. Presence of tibiofibular diastasis is may indicate syndesmotic disruption. The optimum fixation for the syndesmosis has not been defined yet. There is no consensus on how many cortices should be engaged, the ideal screw size, screw composition, the optimum level of placement above the tibial plafond [25]. Commonly, a $3.5 \mathrm{~mm}$ or 4.5 $\mathrm{mm}$ cortical screw are used but this is often governed by the surgeon's preference [26]. It has been shown in some studies the use of two cortical screws over one diastasis screw provide stronger construct biomechanically $[27,28]$. The $4.5 \mathrm{~mm}$ cortical screw provides significant support against forces acting on the syndesmosis during walking [29]. However, in some cases, the syndesmosis screw may be removed prior to full weight bearing at six to eight weeks though some studies have shown no benefit in terms of morbidity when leaving the screw in situ.

An alternative to screw fixation is the use of the Tightrope which consists of a non-biodegradable wire held in place by two cortical metal buttons at either end. This does not routinely require removal, therefore eliminating risks of second anaesthetic and potential cost saving. The drawback with this method is that some patients develop biological reaction to the material. Post operatively, the patients are reviewed in the fracture clinic and remain non weight bearing for at least six weeks [32-34].

\section{Complications and Risk of Arthritis}

Common complications post ankle fractures include arthritis, stiffness, DVT and thrombophlebitis, infection, malunion, non-union and synostosis formation. The risk of these complications varies and is dependent upon the initial fracture pattern, velocity of injury, quality of stabilisation and patient factors. [7,35,36].

In patient with ankle arthritis, it has been reported that up to $70 \%$ have had a history of an ankle injury. Post traumatic osteoarthritis is the most common complication after an ankle fracture and is the most common indication for ankle arthrodesis [37,38]. The ankle joint has a small surface area and bears a lot of weight per unit area and combined with the complex motion of the ankle, incongruency can result in wear of the cartilage and arthritic changes. The more severe the fracture, the more pronounced the arthritic changes. Eighty percent of patients with stable injuries will be asymptomatic after eighteen years. In comparison, $20 \%$ of patients with unstable injuries that undergo operative fixation had radiographical signs of arthritis after six years and while $80 \%$ of patients managed conservatively had radiographical changes after six years [11,39].

Patients with diabetes, peripheral vascular disease, osteoporosis, obesity and those that smoke are associated with a higher risk of poorer outcomes following an ankle fracture fixation due to a combination of factors including poor blood supply, poor bone healing, poor wound healing and the higher weight load through the fracture fixation [40,41]. Diabetics especially pose a challenge with increased risk of infection and hardware failure due to infection, neuropathy, ulcers and poor bone stock. Even amongst diabetics, those with neuropathy are 7.63 times more likely to experience a wound complication than those without neuropathy. The need for further surgery and the development of a Charcot neuropathy is also higher in diabetics with the potential risk of an amputation $[19,42,43]$.

\section{Conclusion}

Ankle fractures are common injuries. Even with a sound understanding of the anatomy, biomechanics and principles of fixation, they can still be a challenge to manage. We have presented a review of the general management and commonly encountered complications. The most common complication is post traumatic osteoarthritis. Diabetic patients and elderly patients are more at risk of particular complications including infection and failure of soft tissue and bone healing. Understanding the associated risks with both non operative or operative management and tailoring management to the needs of the patient will ensure better outcomes for the patient.

\section{References}

1. Mandi DM (2012) Ankle fractures. Clin Podiatr Med Surg 29: 155-186, vii.

2. Buddecke DE Jr, Mandracchia VJ, Pendarvis J (1998) Is this just a sprained ankle? Hosp Med 34: 46-52.

3. Court-Brown CM, Caesar B (2006) Epidemiology of adult fractures: A review. Injury 37: 691-697.

4. Phillips WA, Schwartz HS, Keller CS, Woodward HR, Rudd WS, et al. (1985) A prospective, randomized study of the management of severe ankle fractures. J Bone Joint Surg Am 67: 67-78.

5. Thordarson D (2004) Foot and ankle trauma. Foot Ankle 14: 288-297.

6. Kannus P, Palvanen M, Niemi S, Parkkari J, Jrvinen M (2002) Increasing number and incidence of low-trauma ankle fractures in elderly people: finnish statistics during 1970 â€" 2000 and projections for the future. Bone 31: 430-433.

7. Mehta SS, Rees K, Cutler L, Mangwani J (2014) Understanding risks and complications in the management of ankle fractures. Indian J Orthop 48: 445-452.

8. Sammarco GJ, Burstein AH, Frankel VH (1973) Biomechanics of the ankle: a kinematic study. Orthop Clin North Am 4: 75-96.

9. Carr James B, PGT (1998) Malleolar fractures and soft-tissue injuries of the ankle. Skelet trauma basic Sci Manag Reconstr 2: 2307-2374.

10. Yablon IG, Segal D, Leach RE, Roach JW (1983) Ankle Injuries. J Pediatr Orthop.

11. Ramsey PL, Hamilton W (1976) Changes in tibiotalar area of contact caused by lateral talar shift. J Bone Joint Surg Am 58: 356-357.

12. Zindrick MR, Knight GS, Gogan WJ, Patwardhan AG, Vanderby R, et al. (1984) The efect of fubular shortening and rotation on the biomechanics 
Citation: Seewoonarain S, Prempeh M, Shakokani M, Magan A (2016) Ankle Fractures: Review Article. J Arthritis 5: 188. doi: 10.4172/2167-7921.1000188

Page 4 of 4

of the talocrural joint during various stages of stance phase. Orthop Trans 8: 259-260.

13. Pott $\mathrm{P}$ (2007) Some few general remarks on fractures and dislocations. 1758. Clin Orthop Relat Res 458: 40-41.

14. Danis R (1949) Les fractures malleolaires. Theor Prat losteosynthese Paris Masson.

15. Weber BG (1966) Die verletzungen des oberen sprunggelenkes. Huber.

16. LAUGE-HANSEN N (1950) Fractures of the ankle. II. Combined experimental-surgical and experimental-roentgenologic investigations. Arch Surg 60: 957-985.

17. Piper KJ, Yen-yi JC, Horsley M (2010) Missed posterior deep, inferior subcompartment syndrome in a patient with an ankle fracture: a case report. J Foot Ankle Surg 49: 398.

18. Maisonneuve JG (1840) Recherches sur la fracture du pÃ๑ronÃ $\odot$. Arch Gen Med 7: 165-187.

19. Costigan W, Thordarson DB, Debnath UK (2007) Operative management of ankle fractures in patients with diabetes mellitus. Foot Ankle Int 28 : 32-37.

20. Nasell H, Ottosson C, Tornqvist H, Linde J, Ponzer S (2011) The impact of smoking on complications after operatively treated ankle fractures--a follow-up study of 906 patients. J Orthop Trauma 25: 748-755.

21. Ali AM, Noyes D, Cogswell LK (2013) Management of open fractures of the lower limb. Br J Hosp Med (Lond) 74: 577-580.

22. Nanchahal J, Nayagam S, Khan U, Moran C, Barrett S, et al. (2009) Standards for the management of open fractures of the lower limb.

23. http://www.spitjudms.ro/_files/protocoale_terapeutice/ortopedie/ managementul\%20fracturii\%20deschise $\% 20 \mathrm{de} \% 20$ tibie.pdf

24. Yde J, Kristensen KD (1980) Ankle fractures: supination-eversion fractures of stage IV. Primary and late results of operative and nonoperative treatment. Acta Orthop Scand 51: 981-990.

25. Magan A, Golano P, Maffulli N, Khanduja V (2014) Evaluation and management of injuries of the tibiofibular syndesmosis. Br Med Bull 111: 101-115.

26. Bava E, Charlton T, Thordarson D (2010) Ankle fracture syndesmosis fixation and management: the current practice of orthopedic surgeons. Am J Orthop (Belle Mead NJ) 39: 242-246.

27. Beumer A, Campo MM, Niesing R, Day J, Kleinrensink G-J, et al. (2005) Screw fixation of the syndesmosis: a cadaver model comparing stainless steel and titanium screws and three and four cortical fixation. Injury 36 : 60-64.

28. Xenos JS, Hopkinson WJ, Mulligan ME, Olson EJ, Popovic NA (1995) The tibiofibular syndesmosis. Evaluation of the ligamentous structures, methods of fixation, and radiographic assessment. J Bone Joint Surg Am 77: 847-856.

29. Hansen M, Le L, Wertheimer S, Meyer E, Haut R (2006) Syndesmosis fixation: analysis of shear stress via axial load on $3.5-\mathrm{mm}$ and $4.5-\mathrm{mm}$ quadricortical syndesmotic screws. J Foot Ankle Surg 45: 65-69.

30. Naqvi GA, Shafqat A, Awan N (2012) Tightrope fixation of ankle syndesmosis injuries: clinical outcome, complications and technique modification. Injury 43: 838-842.

31. Qamar F, Kadakia A, Venkateswaran B (2011) An anatomical way of treating ankle syndesmotic injuries. J Foot Ankle Surg 50: 762-765.

32. RÃedi TP, Buckley RE, CGM (2007) AO principles of fracture management. Theme Medical Publishers, Germany.

33. Appleton P, McQueen M, Court-Brown C (2006) The Fibula Nail for Treatment of Ankle Fractures in Elderly and High Risk Patients. Tech Foot Ankle Surg 5: 204-208.

34. Schepers $\mathrm{T}$ (2011) To retain or remove the syndesmotic screw: a review of literature. Arch Orthop Trauma Surg 131: 879-883.

35. SooHoo NF, Krenek L, Eagan MJ, Gurbani B, Ko CY, et al. (2009) Complication rates following open reduction and internal fixation of ankle fractures. J Bone Joint Surg Am 91: 1042-1049.

36. Donken CC, Al-Khateeb H, Verhofstad MH, van Laarhoven CJ (2012) Surgical versus conservative interventions for treating ankle fractures in adults. Cochrane Database Syst Rev 8: CD008470.

37. Thomas RH, Daniels TR (2003) Ankle arthritis. J Bone Joint Surg Am 85-85A: 923-36.

38. Horisberger M, Valderrabano V, Hintermann B (2009) Posttraumatic ankle osteoarthritis after ankle-related fractures. J Orthop Trauma 23: 60-67.

39. Gougoulias N, Khanna A, Maffulli N (2010) How successful are current ankle replacements?: a systematic review of the literature. Clin Orthop Relat Res 468: 199-208.

40. Kristensen KD, Hansen T (1985) Closed treatment of ankle fractures. Stage II supination-eversion fractures followed for 20 years. Acta Orthop Scand 56: 107-109.

41. Sloan A, Hussain I, Maqsood M, Eremin O, El-Sheemy M (2010) The effects of smoking on fracture healing. Surgeon 8: 111-116.

42. Zalavras CG, Christensen T, Rigopoulos N, Holtom P, Patzakis MJ (2009) Infection following operative treatment of ankle fractures. Clin Orthop Relat Res 467: 1715-1720.

43. Dodson NB, Ross AJ, Mendicino RW, Catanzariti AR (2013) Factors affecting healing of ankle fractures. J Foot Ankle Surg 52: 2-5. 